\title{
Outcome of patient with high-risk chronic myelomonocytic leukemia, treated with decitabine prior to transformation to acute myeloid leukemia: A case report
}

\author{
HUAN LIU ${ }^{1 *}$, JUAN CHENG $^{2 *}$, LONG ZHAO $^{2}$, QIAN XU ${ }^{1}$, MINGMING XUE $^{1}$, SHULING ZHANG $^{1}$ and BEI LIU ${ }^{2}$ \\ ${ }^{1}$ The First Clinical Medical College, Lanzhou University, Lanzhou; ${ }^{2}$ Department of Hematology, \\ The First Affiliated Hospital of Lanzhou University, Lanzhou, Gansu 730000, P.R. China
}

Received March 17, 2017; Accepted January 29, 2018

DOI: $10.3892 / \mathrm{ol} .2018 .8236$

\begin{abstract}
The present study describes a patient with high-risk chronic myelomonocytic leukemia (CMML), for whom decitabine therapy achieved partial remission, prior to a sudden transformation to acute myeloid leukemia (AML) and an inferior outcome. The 53-year-old male reported easily bruising for 5 months. Examination indicated a diagnosis of CMML. Chromosome analysis identified a 48, XY, +8, +21 karyotype, classifying the patient as high-risk, according to a clinical/molecular CPSS (CPSS-Mol) model. Gene sequencing detected a mutation in DNA methyltransferase $3 \alpha$, which is relatively rarely identified in CMML and has recently been reported to have an independent prognostic impact on overall survival time. Partial remission was achieved with decitabine treatment, and hematologic improvement was observed subsequent to 2 cycles of treatment. However, a sudden transformation to AML led to fatality of the patient. This case suggests that decitabine may be an effective therapeutic for high-risk CMML; however, the response may be temporary, and the ultimate outcome may be extremely poor. Therefore, novel treatment strategies of CMML, including combination therapies with decitabine, or targeted drugs, including Janus kinase inhibitors or granulocyte-macrophage colony stimulating factor monoclonal antibodies, require investigation.
\end{abstract}

Correspondence to: Dr Bei Liu, Department of Hematology, The First Affiliated Hospital of Lanzhou University, 1 Donggangxilu Street, Lanzhou, Gansu 730000, P.R. China

E-mail: liubeiff@163.com

${ }^{*}$ Contributed equally

Key words: chronic myelomonocytic leukemia, acute myeloid leukemia, DNA methyltransferase $3 \alpha$ mutation, decitabine, partial remission

\section{Introduction}

Chronic myelomonocytic leukemia (CMML) is a form of myeloid neoplasm with dysplastic and proliferative features. It is defined by the presence of persistent peripheral blood (PB) monocytosis $\left(\geq 1 \times 10^{9} / /\right)$, when monocytes account for $\geq 10 \%$ of the White Blood Cell (WBC) count (1). Other disorders, including Philadelphia (Ph) chromosome, BCR, RhoGEF and GTPase activating protein/proto-oncogene tyrosine-protein kinase ABL1 (BCR-ABL1) fusion gene, and rearrangements of platelet derived growth factor receptor $\alpha$ (PDGFR $\alpha$ ), platelet derived growth factor receptor $\beta$ (PDGFR $\beta)$ and fibroblast growth factor receptor 1 (FGFR1), require exclusion prior to diagnosis (2). The French-American-British (FAB) classification (3) and World Health Organization (WHO) (4) have classified CMML into 2 subtypes (CMML-I and -II), according to leukocyte count and the proportion of bone marrow (BM) blasts, respectively.

Due to the heterogeneity of the disease, the clinical course and outcomes of patients with CMML are variable (5). A number of prognostic studies have been performed, in which cytogenetic and molecular abnormalities were indicated to be important prognostic factors. Cytogenetic abnormalities, including trisomy 8, complex karyotypes, monosomy 7, del7q, trisomy 21 , and -Y, have been identified to have prognostic value (6). Patients with trisomy 8 , complex karyotypes, monosomy 7 and del7q are classified as high-risk according to the majority of prognostic models (7), and exhibit a higher leukemic transformation rate and shorter overall survival time (6-8). A number of molecular abnormalities are commonly exhibited by patients with CMML, including mutations in additional sex combs like transcriptional regulator 1 (ASXL1), Tet methylcytosine dioxygenase 2 (TET2), serine and arginine rich splicing factor 2 (SRSF2), NRAS proto-oncogene, GTPase (NRAS), runt related transcription factor 1 (RUNX1), SET binding protein 1 (SETBP1), Cbl proto-oncogene (CBL), JAK2 and RUNX1 are common, while mutations in RUNX1, NRAS, SETBP1 and ASXL1, are independently associated with inferior overall survival (OS) time (9).

The present case study describes a high-risk patient with CMML, who achieved PR for 2 months with decitabine therapy. However, the patient demonstrated a sudden transformation 
to AML and eventually an inferior outcome, indicating that decitabine treatment as a single agent may not be satisfactory for CMML cases that have a tendency to transform to AML. This highlights the requirement to discover novel treatment strategies for CMML.

\section{Case report}

In September 2015, a 53-year-old man was admitted in The First Affiliated Hospital of Lanzhou University (Lanzhou, China), having bruised easily for $\sim 5$ months. PB analysis revealed a white blood cell count (WBC) of $35.07 \times 10^{9}$ cells $/ 1$, a monocyte level of $4.46 \times 10^{9}$ cells/l, a hemoglobin $(\mathrm{Hb})$ level of $74 \mathrm{~g} / 1$ and a platelet count of $44.0 \times 10^{9}$ cells $/ 1$. A bone marrow aspirate examination using Wright-Giemsa stain revealed a cell proportion of $6.5 \%$ myeloblasts, $2.5 \%$ promyelocyte, $10.5 \%$ promonocytes and $20 \%$ immature monocytes. (Fig. 1), resulting in a diagnosis of CMML according to the $2008 \mathrm{WHO}$ myelodysplastic (MDS)/myeloproliferative neoplasms classification system (2). Immunophenotyping analysis revealed that the blasts were positive for cytoplasmic myeloperoxidase antigens and cluster of differentiation (CD)64, 11c, 13, 11b and 33, and negative for CD7, 117, 3, 16, 20, 10, 19, 56, 4 and 34, and cytoplasmic CD79a and CD3 antigens, which were detected on the surface of the monoblasts by multiparameter flow cytometry. A total of $2 \mathrm{ml}$ bone marrow was extracted using a heparin anticoagulation solution (25 IU heparin sodium; BD Biosciences, Franklin Lakes, NJ, USA) at $15-25^{\circ} \mathrm{C}$ for $30 \mathrm{~min}$. The concentration of marrow mononuclear cells specimen was adjusted to $5 \times 10^{9}$ cells $/ 1$, and fluorescent labeling antibody reagents, FITC, PE, PerCP or APC (all from BD Biosciences) were added. The solutions were protected from light and incubated for $15 \mathrm{~min}$. A total of $2 \mathrm{ml}$ Red Blood Cell Lysis Buffer was added to each sample and incubated for $10 \mathrm{~min}$ at room temperature in darkness. The sampled were then centrifuged at $40 \mathrm{x} \mathrm{g}$ for $6 \mathrm{~min}$, and the supernatant was discarded. The remaining sample was washed twice in PBS, and cells resuspended in PBS for detection using a FACSCalibur full automatic multicolor analysis flow cytometer system (BD Biosciences) using FlowJo version 10.2 software (FlowJo LLC, Ashland, OR, USA).

Giemsa $(\mathrm{G})$ banding analysis required preparation by adding $3 \mathrm{ml} 0.25 \%$ trypsin (BD Biosciences) solution to $45 \mathrm{ml}$ $0.85 \%$ saline, with a $\mathrm{pH}$ of $6.8-7.2$, and warmed to $37^{\circ}$ using a water bath. Chromosome specimens were digested in trypsin solution at $37^{\circ} \mathrm{C}$ for $2-3 \mathrm{~min}$, then swiftly rinsed with $0.85 \%$ saline to terminate trypsin activity. This was followed by Giemsa staining (5 ml; BD Biosciences) for $15 \mathrm{~min}$ at $32^{\circ} \mathrm{C}$ and then the slides were rinsed with tap water and air dried. The staining was observed under a low power light microscope (magnification, $\mathrm{x} 10$ ) and the metaphase of mitosis was observed. Then an oil objective (magnification, x100) was used to observe Giemsa $(\mathrm{G})$ banding. $\mathrm{G}$ banding analysis did not detect $\mathrm{Ph}$ chromosome.

Total RNA was isolated from the bone marrow aspirate using TRIzol (Thermo Fisher Scientific, Inc., Waltham, MA, USA, according to the manufactuerer's protocol. Reverse transcription of was performed using a reverse transcription kit (Takara Bio, Inc., Otsu, Japan). The temperature protocol was as follows: $37^{\circ} \mathrm{C}$ for $15 \mathrm{~min}, 85^{\circ} \mathrm{C}$ for $5 \mathrm{sec}$ and kept at $4^{\circ} \mathrm{C}$ until use. The fluorophore used for the reverse transcription-quantitative polymerase chain reaction (RT-qPCR; Takara Biotechnology Co., Ltd., Dalian, China) was Dalian's Tap enzyme (Takara Bio, Inc.). The target gene primers were as follows: BCR-ABL, bcr-abl, forward, 5'-AGGGTG CACAGCCGCAACGGC-3', reverse 5'-GGCTTCACTCAG ACCCTGAGG-3'. The reference gene was $\beta$-actin. The reference gene primers were as follows: $\beta$-actin, forward, 5'-GGAGATTACTGCCCTGGCTCCTA-3' and reverse, 5'-GACTCATCGTACTCCTGCTTGCTG-3'. The thermocycling conditions were as follows: $95^{\circ} \mathrm{C}$ for $30 \mathrm{sec}$, then 40 cycles at $95^{\circ} \mathrm{C}$ for $5 \mathrm{sec}$ and $60^{\circ} \mathrm{C}$ for $20 \mathrm{sec}$. The results were expressed as $2^{-\Delta \Delta C q}(10)$. The quantity of BCR-ABL transcript was normalized to the ABL expression level. The copy number of BCR-ABL fusion gene and the copy number of $\mathrm{ABL}$ were calculated, and the result was expressed as the ratio of BCR-ABL copy number to ABL copy number. RT-qPCR did not detect BCR-ABL1 gene fusion for this patient.

Fluorescence in situ hybridization demonstrated that PDGFR $\alpha$, PDGFR $\beta$ and FGFR1 were not rearranged (Fig. 2). The method was performed using 4 genes locus specific probes for ASS, PDGFR $\alpha$, PDGFR $\beta$ and FGFR, localized at 9q34, 4q12, 5q32-33 and 8p12, respectively (all from Kindstar Global, Hester Clinical Inspection, Beijing, China). Bone marrow blood $(3 \mathrm{ml})$ was extracted and the sampled centrifuged at $250 \mathrm{x} \mathrm{g}$, room temperaure for $8 \mathrm{~min}$ and the supernatant discarded. Potassium chloride $(5 \mathrm{ml})$ was added and the samples incubated at $37^{\circ} \mathrm{C}$ for $20 \mathrm{~min}$. The chromosome specimens stored at $-20^{\circ} \mathrm{C}$, were then fixed with methanol and glacial acetic acid (3:1) for $30 \mathrm{~min}$ at $37^{\circ} \mathrm{C}$. The slide obtained from the previous step were bathed in $2 \mathrm{x}$ SSC solution (2x SSC solution configuration method: Nacl $175.5 \mathrm{~g}$, trisodium citrate $88.2 \mathrm{~g}$, add $1,000 \mathrm{ml} \mathrm{ddH}_{2} \mathrm{O}, \mathrm{PH}$ adjusted to 5.3. Add $\mathrm{ddH}_{2} \mathrm{O}$ and diluted with 1:9, adjusted $\mathrm{pH}$ to 7.0 ) at $37^{\circ} \mathrm{C}$ for $10 \mathrm{~min}$, so as to increase cell permeability, simulate cell physiological environment and ensure the stability of the test substances, prior to graded dehydration in 70,85 and $100 \%$ ethanol at room temperature. Denaturation took place in $70 \%$ formamide and $2 \mathrm{x} \mathrm{SSC}$, at $72^{\circ} \mathrm{C}$ for $3 \mathrm{~min}$. A total of $10 \mu \mathrm{l}$ probe mixture, with $5 \mu \mathrm{l}$ probe, $3 \mu \mathrm{l}$ DNA specimen, $0.5 \mu \mathrm{l}$ salmon sperm DNA and $1.5 \mu 1 \mathrm{H}_{2} \mathrm{O}$ was incubated for $10 \mathrm{~min}$ in a water bath at $72^{\circ} \mathrm{C}$, then placed in an iced water bath for $5 \mathrm{~min}$, and finally a $37^{\circ} \mathrm{C}$ water bath for $5 \mathrm{~min}$. The specimens were mounted onto glass slides using RubberCement (Kindstar Global, Beijing, China) and placed at $37^{\circ} \mathrm{C}$ overnight for hybridization. Specimens were washed for $5 \mathrm{~min}$ at $72^{\circ} \mathrm{C}$ in $0.4 \mathrm{x} \mathrm{SSC}$ and then for $2 \mathrm{~min}$ with $0.1 \%$ TritonX-100 at room temperature. DAPI (Kindstar Global) was added to PBS and a $10 \mu \mathrm{g} / \mathrm{ml}$ DAPI solution was prepared, and the specimens incubated at $37^{\circ} \mathrm{C}$ for $15 \mathrm{~min}$. Fluorescence hybridization signals of interphase cells were observed under the excitation of UV/Texas red/FITC trichromatic filters with an Olympus BX60 fluorescence microscope (Olympus Corporation, Tokyo, Japan). A total of 400 probe mixture cells were analyzed at one time. Image acquisition was achieved using an autosomal auto analysis system (Kindstar Global). This allowed a CMML diagnosis to be made. In addition, conventional cytogenetic analysis performed using the $G$ banding technique 

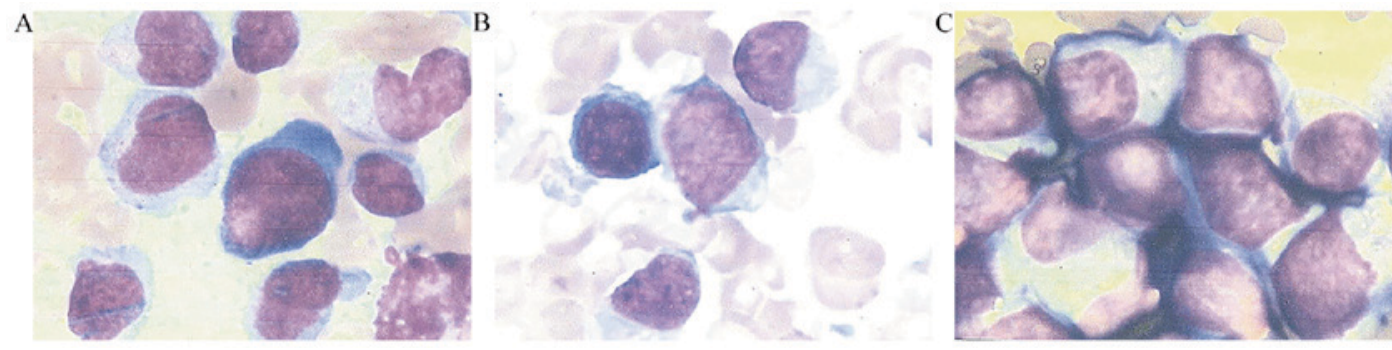

Figure 1. Normocellular bone marrow aspirate of the subject patient, containing (A) myeloblasts, promonocytes and immature monocytes. (B) Following 3 cycles of decitabine treatment, the proportion of bone marrow blasts was $<5 \%$, and (C) the level of monoblasts increased to $59 \%$. Magnification, x100.
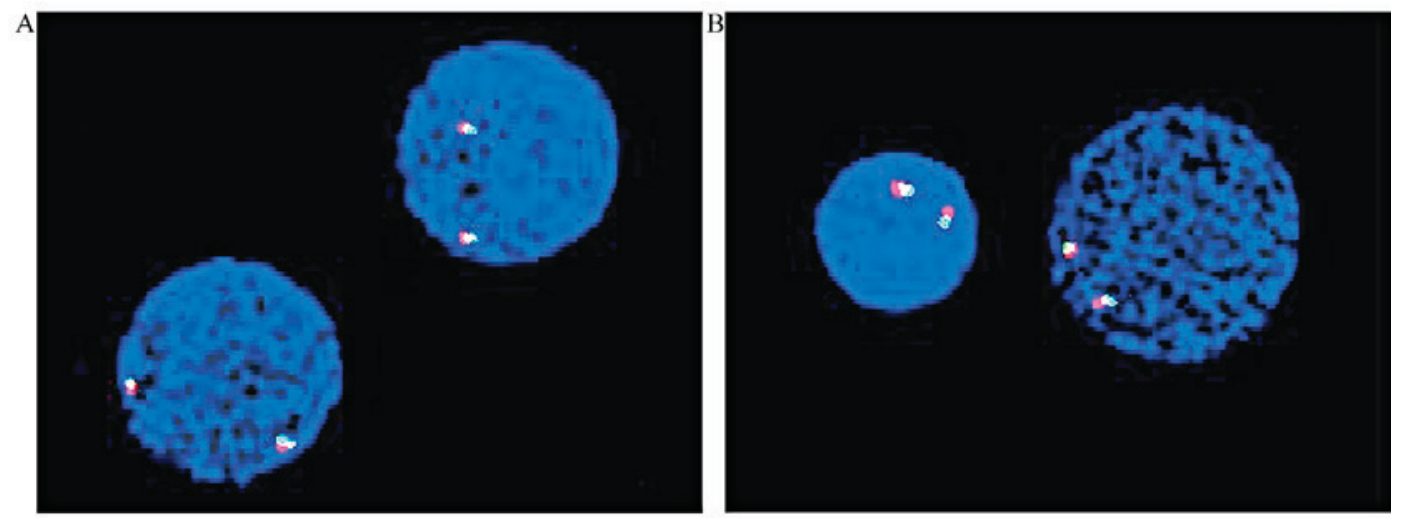

Figure 2. Fluorescence in situ hybridization analysis demonstrated no evidence of (A) PDGFR $\alpha$ or (B) PDGFR $\beta$ rearrangement. PDGFR $\alpha$, platelet derived growth factor receptor $\alpha$; PDGFR $\beta$, platelet derived growth factor $\beta$.

revealed a $48, \mathrm{XY},+8$ and +21 karyotype in all 20 metaphase cells (Fig. 3).

Meanwhile, gene sequencing using a polymerase chain reaction binding-based sequencing method, performed externally (Shanghai Di Shuo Becken Ltd Medical Examination, Shanghai, China), detected a missense mutation in DNMT3A (Fig. 4A) and nonsense mutations in TET2 (Fig. 4B). There was no evidence of mutations in SF3B1, SRSF2, ASXL1, RUNX1, FLT3-ITD, C-kit/D816V, NPM1 or CEBPA. According to these cytogenetic abnormalities, the case was defined as high-risk CMML.

The patient was treated with decitabine, administered at $25 \mathrm{mg}$ daily for 5 consecutive days every 28 days. The patient underwent 3 courses of this regimen. The BM response was examined following each treatment cycle. Following 2 cycles of therapy, the patient achieved partial remission, classified according to the modified International Working Group response criteria in myelodysplastic syndromes (MDS) (11). The level of BM blasts had decreased to $<5 \%$ and the percentage reduction was $>50 \%$. Furthermore, the patient's diagnosis was altered from CMML-II to CMML-I according to the FAB subtype criteria. Following 3 cycles of therapy, the patient maintained PR and displayed hematologic improvement (HI), including erythroid and platelet responses (11). The majority of parameters had improved, including an increase in $\mathrm{Hb}$ level from 56-168 g/l and an increase in platelet level from $2.1 \times 10^{10}-6.2 \times 10^{10} / 1$. BM aspirate analysis revealed a proportion of $2.5 \%$ myeloblasts and $0 \%$ promonocytes (Fig. 1B).

Subsequent to 3 cycles of decitabine therapy, the level of lactate dehydrogenase progressively increased from

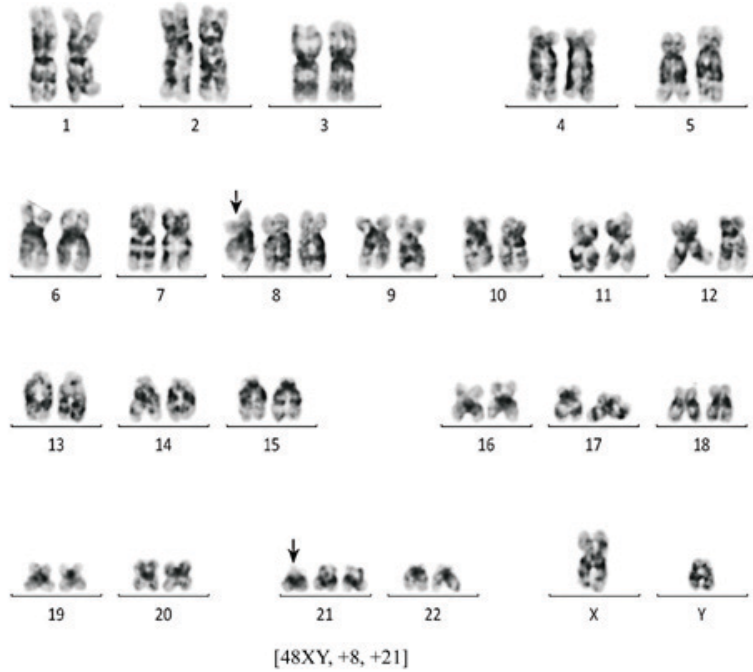

Figure 3. Representation of the 48, XY, $+8,+21$ karyotype.

267 to $11,347 \mathrm{U} / 1$ and absolute monocytosis (AMC) was detected (from $0.32 \times 10^{9}$ to $1.86 \times 10^{9}$ cells/l), potentially indicating disease progression. PB examination confirmed a WBC of $13.4 \times 10^{9} / 1,81 \mathrm{~g} \mathrm{Hb} / 1,32 \times 10^{9}$ platelets/l and $11347 \mathrm{U}$ lactate dehydrogenase/l. BM aspirate analysis revealed $73.5 \%$ myeloblasts and 59\% monoblasts (Fig. 1C). BM biopsy demonstrated a trend towards AML-M5. A diagnosis of disease transformation to AML-M5 was made, and fatality of the patient occurred 1 month after AML transformation, and prior to any AML treatment. 
A

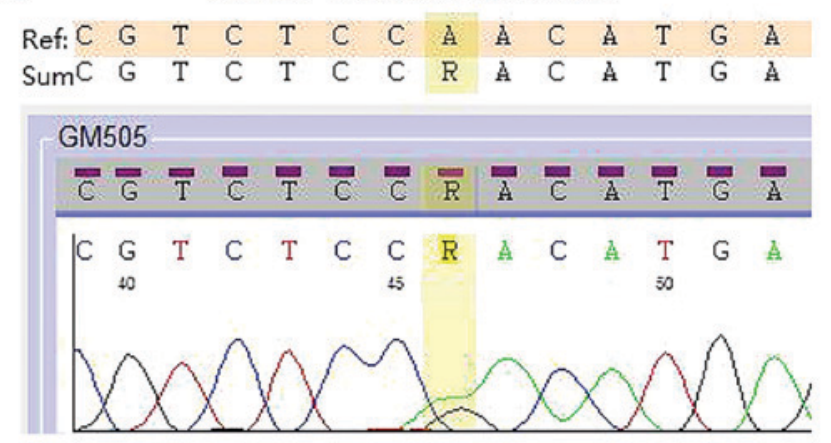

B

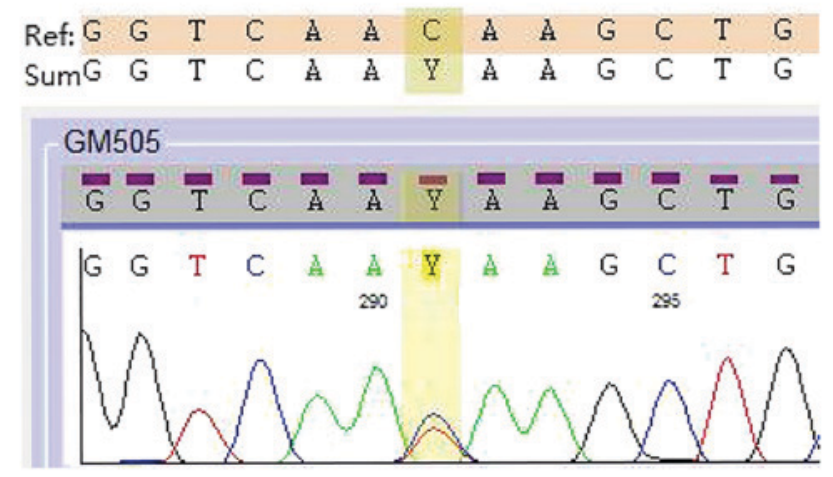

Figure 4. Results of gene sequencing. (A) A missense mutation in DNMT3A was detected, and (B) a nonsense mutation in TET2 was detected. DNMT3A, DNA methyltransferase $3 \alpha$; TET2, Tet methylcytosine dioxygenase 2 .

\section{Discussion}

CMML is a clonal stem cell disorder, with characteristics of myeloproliferative and myelodysplastic neoplasms (1). Due to the heterogeneity of the disease, it is associated with variable clinical courses and outcomes, and an inherent tendency to transform to AML. CMML-I has a 14\% chance and CMML-II has a $24 \%$ chance of developing into AML within 2 years, increasing to 18 and $63 \%$ after 5 years, respectively (4). To date, a number of clinical parameters have been reported to be associated with poor survival time of patients with CMML, including age, sex, Eastern Cooperative Oncology Group performance status (12), Hb level, WBC count, number of circulating immature myeloid cells, proportion of BM blasts, karyotype and $\beta 2$-microglobulin/lactate dehydrogenase levels $(13,14)$. Furthermore, previous reports have demonstrated that a high proportion of BM blasts, elevated lactate dehydrogenase, male sex and a low $\mathrm{Hb}$ level were independent prognostic factors (15). Most recently, cytogenetic status and specific gene mutations have been identified as important prognostic factors, and have been incorporated into the CMML risk stratification system $(7,16)$.

In the present case, a $48, \mathrm{XY},+8,+21$ karyotype was detected by conventional cytogenetic analysis. Clonal cytogenetic abnormalities have been reported in $>30 \%$ CMML cases (17). Multiple prognostic models have been defined to stratify CMML patients into different risk categories, based on the Global MD Anderson Prognostic Scoring system (G-MDAPS) $(8,18)$, Spanish cytogenetic risk stratification system (14) and CMML-specific prognostic scoring system
(CPSS) $(18,19)$. These systems stratify patients based on cytogenetic abnormalities and are effective in predicting survival and leukemic transformation (17). Furthermore, certain prognostic models, including The Groupe Francophone des Myelodysplasies (GFM) (15) and Mayo Molecular Model (MMM) (15) integrate gene mutation into risk assessment, which significantly improves the risk stratification of CMML. In an international collaborative study, Elena et al (9) proposed a specific prognostic score based on 260 CMML patients, called the CPSS-Mol (9). This score integrated karyotype with genetic mutation, red blood cell transfusion dependence, WBC count and percentage of BM blasts. It stratified CMML patients into 4 different risk groups that had significantly different median OS times and incidences of leukemic progression (9). The patient discussed in the present study exhibited cytogenetic abnormalities of trisomy 8 and trisomy 21, which are classified as high-risk factors according to the majority of prognostic models, including the CPSS-Mol. Such cases are considered to have a high leukemic transformation rate and shorter OS time.

Molecular abnormalities are identified in $>90 \%$ CMML patients (20). Genetic sequencing identified DNMT3A and TET2 mutations in the patient discussed in the present study. These genes are involved in epigenetic regulation and DNA methylation. Mutations in DNMT3A, located on chromosome 2 q23.3, are identified in 2-5\% patients with CMML (21). Considering this low frequency, its prognostic value has not been investigated. Itzykson et al (16) reported that DNMT3A does not impact OS or leukemia-free survival (LFS). In addition, Jaiswal et al (22) indicated that DNMT3A is associated with age-associated clonal hematopoiesis and increased overall mortality. However, a recent study by Patnaik et al (21) indicated that DNMT3A mutations are independent prognostic factors of an inferior OS time. Patients with DNMT3A mutations were demonstrated to be more likely to exhibit low hemoglobin levels, high monocyte counts, a high proportion of bone marrow blasts and abnormal karyotypes. Considering rare DNMT3A mutations have an independent prognostic impact on survival, the gene may be integrated into CMML prognostic models.

TET2 is a member of the TET family, and is located on chromosome $4 q 24$. Mutations in this gene are identified in $>60 \%$ CMML patients (15). However, to the best of our knowledge, it has not been associated with OS nor LFS, and the prognostic value of TET2 mutations in CMML remains controversial. Previous research has suggested that TET2 mutations have an adverse effect in patients with CMML $(23,24)$. However, other studies have suggested a relatively good prognosis for patients with CMML patients carrying TET2 mutations. For example, Patnaik et al (25) demonstrated that the presence of clonal TET2 mutations in the absence of clonal ASXL1 mutations has a favorable effect on OS time. In addition, mutations in TET2 are associated with an improved response to hypomethylating agents (HMAs) (26). However, the prognostic impact of TET2 mutation remains unclear. Furthermore, although the interaction between TET2 and ASXL1 has been studied, the association between TET 2 and other genes, including DNMT3A, remain unknown. Therefore, a more comprehensive genomic analysis is required in to study the interaction between TET2 and DNMT3A, and to confirm the exact role of these genes. 
Due to the heterogeneity of CMML, there exists no standard therapy. Available treatments include chemotherapy, allogeneic stem cell transplantation (HCT) and HMAs (decitabine and azacitidine) (15). Chemotherapies, including etoposide, cytarabine, topotecan and lonafarnib, have been reported to have poor response rates and severe toxicities (15). Although HCT currently remains the only potentially curative therapeutic strategy for CMML, in the case of old age, poor cytogenetics or high-risk classification, this treatment is not effective (27-29). HMAs, which are approved by the Food and Drug Administration (FDA), remain the safest and most efficient mode of therapy, and the main mode of treatment for high risk CMML (30). Compared with HCT, HMAs are often considered as a first line treatment for patients with CMML-II a high proportion of BM blasts (31). Kantarjian et al (32) demonstrated that decitabine treatment was associated with a survival advantage in patients with high-risk MDS compared with intensive chemotherapy. Although these studied $(30,31)$ confirmed the therapeutic effect of HMA in CMML. However the overall response rate (ORR) and complete remission rate (CR) are low, previous studies have indicated that the ORR of patients to HMAs is $\sim 30-40 \%$, with CR only $15 \%(15,33)$. In addition, the responses may not be sustained, and can lead to poor OS time and transformation to high risk phenotypes. However, one study described a patient with AML, transformed from CMML, who reached complete remission with decitabine combined with a low dose of cytarabine, aclarubicin and granulocyte colony-stimulating factor (34). Although the results did not have statistical significance, they may offer insight into potential therapeutic strategies for AML, transformed from CMML.

The case described in the present study is relatively rarely observed. However, previous research has demonstrated that loss of response to decitabine in patients who had reached remission from CMML is not uncommonly. For example, Padron et al (35) discussed that while the use of decitabine in CMML is FDA-approved, but HMA cannot offer meaningful potential to change the natural history of the disease. In addition, The effectiveness of HMAs is temporary and survival after loss of response is dismal (15). Patnaik et al (15) demonstrated that the overall response rates of HMA are about $30-40 \%$, with complete remission rates of $15 \%$. However, the responses are generally not sustained, and the OS time, subsequent to loss of response, is often poor. The results inferred from the present study corroborate these conclusions. Thus, investigation into novel strategies to treat such patients are urgently required.

A number of targeted therapy drugs are currently in preclinical studies, including anti-granulocyte-macrophage colony stimulating factor (GM-CSF) antibodies (36) and JAK inhibitors $(35,37)$. Early studies have demonstrated that GM-CSF hypersensitivity is a hallmark of juvenile myelomonocytic leukemia (JMML) (38). A previous study demonstrated that the majority of CMML cases exhibit GM-CSF hypersensitivity, indicating a potential therapeutic target in reducing CMML cell proliferation via GM-CSF neutralization with targeted anti-GM-CSF monoclonal antibodies or JAK inhibitors (36). Padron et al (36) demonstrated that GM-CSF-dependent phosphorylated-signal transducer and activator of transcription sensitivity has therapeutic potential in CMML. A phase I trial of ruxolitinib, JAK1/2 inhibitor, conducted by Padron et al (35), identified that ruxolitinib is as safe to administer as pacritinib and momelotinib, with good tolerance and minimal toxicity. In addition, the drugs demonstrated a broad range of activity in hematologic, spleen and symptom response, and correlative analysis highlighted the ruxolitinib-associated cytokine depletion in CMML (35). In addition, a previous study identified that treatment with JAK inhibitors may be downregulated in several genes, including the inflammatory response in myeloproliferative neoplasms (39).

However, the current treatment regime for CMML, and the available therapy for AML transformed from CMML is limited. Based on its aforementioned success, decitabine requires further investigation to be used in combination therapies for CMML. Considering decitabine can temporarily improve CMML and that HCT remains the only potentially curative therapeutic strategy, we suggest that timely hematopoietic stem cell transplantation is necessary. Novel targeted therapies, including JAK inhibitors and targeted anti-GM-CSF monoclonal antibodies, are being developed. These are promising for use in patients with high-risk CMML, which has a tendency to transform to AML.

\section{Conclusion}

In the patient presented in the present study, the trajectory of a sudden transformation from CMML, with a high risk of molecular and cytogenetic abnormalities, into AML was observed during decitabine treatment. Although the patient achieved partial remission, an aggressive clinical course and inferior outcome followed, indicating that the identified molecular and cytogenetic abnormalities may have accelerated the course of disease and resulted in its rapid progression. Thus, decitabine as a single agent was unable to produce satisfactory results in high-risk CMML, and novel targeted treatment strategies, are urgently required.

\section{Acknowledgements}

Not applicable.

\section{Funding}

No funding was received.

\section{Availability of data and materials}

The analyzed data sets generated during the study are available from the corresponding author, on reasonable request.

\section{Author contributions}

HL contributed to the conception of the study, and was a major contributor in writing the manuscript. JC designed the study and conducted the analysis. LZ helped perform the analysis and discussions. QX, MMX and SLZ were responsible for data acquisition. BL interpreted the results. The final version of the manuscript was read and approved by all authors. 


\section{Ethics approval and consent to participate}

The patient provided informed consent for participation in the present study.

\section{Consent for publication}

Not applicable.

\section{Competing interests}

The authors declare that they have no competing interests.

\section{References}

1. Arber DA, Orazi A, Hasserjian R, Thiele J, Borowitz MJ, Le Beau MM, Bloomfield CD, Cazzola M and Vardiman JW: The 2016 revision to the World Health Organization classification of myeloid neoplasms and acute leukemia. Blood 127: 2391-2405, 2016.

2. Vardiman JW, Thiele J, Arber DA, Brunning RD, Borowitz MJ, Porwit A, Harris NL, Le Beau MM, Hellström-Lindberg E, Tefferi A and Bloomfield CD: The 2008 revision of the World Health Organization (WHO) classification of myeloid neoplasms and acute leukemia: Rationale and important changes. Blood 114: 937-951, 2009.

3. Bennett JM, Catovsky D, Daniel MT, Flandrin G, Galton DA, Gralnick H, Sultan C and Cox C: The chronic myeloid leukaemias: Guidelines for distinguishing chronic granulocytic, atypical chronic myeloid, and chronic myelomonocytic leukaemia. Proposals by the French-American-British cooperative leukaemia group. Br J Haematol 87: 746-754, 1994

4. Germing U, Strupp C, Knipp S, Kuendgen A, Giagounidis A, Hildebrandt B, Aul C, Haas R, Gattermann N and Bennett JM: Chronic myelomonocytic leukemia in the light of the WHO proposals. Haematologica 92: 974-977, 2007.

5. Zandberg DP, Huang TY, Ke X, Baer MR, Gore SD, Smith SW and Davidoff AJ: Treatment and outcomes for chronic myelomonocytic leukemia compared to myelodysplastic syndromes in older adults. Haematologica 98: 584-590, 2013.

6. Wassie EA, Itzykson R, Lasho TL, Kosmider O, Finke CM, Hanson CA, Ketterling RP, Solary E, Tefferi A and Patnaik MM: Molecular and prognostic correlates of cytogenetic abnormalities in chronic myelomonocytic leukemia: A Mayo clinic-french consortium study. Am J Hematol 89: 1111-1115, 2014.

7. Patnaik MM and Tefferi A: Cytogenetic and molecular abnormalities in chronic myelomonocytic leukemia. Blood Cancer J 6: e393, 2016

8. Benton CB, Nazha A, Pemmaraju N and Garcia-Manero G: Chronic myelomonocytic leukemia: Forefront of the field in 2015. Crit Rev Oncol Hematol 95: 222-242, 2015.

9. Elena C, Galli A, Such E, Meggendorfer M, Germing U, Rizzo E, Cervera J, Molteni E, Fasan A, Schuler E, et al: Integrating clinical features and genetic lesions in the risk assessment of patients with chronic myelomonocytic leukemia. Blood 128 1408-1417, 2016.

10. Livak KJ and Schmittgen TD: Analysis of relative gene expression data using real-time quantitative PCR and the 2(-Delta Delta C(T)) method. Methods 25: 402-408, 2001.

11. Cheson BD, Greenberg PL, Bennett JM, Lowenberg B, Wijermans PW, Nimer SD, Pinto A, Beran M, de Witte TM, Stone RM, et al: Clinical application and proposal for modification of the International Working Group (IWG) response criteria in myelodysplasia. Blood 108: 419-425, 2006.

12. Bennett JM, Andersen JW and Cassileth PA: Long term survival in acute myeloid leukemia: The Eastern Cooperative Oncology Group (ECOG) experience. Leuk Res 15: 223-227, 1991.

13. Patnaik MM, Wassie EA, Lasho TL, Hanson CA, Ketterling R and Tefferi A: Blast transformation in chronic myelomonocytic leukemia: Risk factors, genetic features, survival, and treatment outcome. Am J Hematol 90: 411-416, 2015.

14. Tang G, Fu B, Hu S, Lu X, Tang Z, Li S, Jabbar K, Khoury JD, Medeiros LJ and Wang SA: Prognostic impact of acquisition of cytogenetic abnormalities during the course of chronic myelomonocytic leukemia. Am J Hematol 90: 882-887, 2015.
15. Patnaik MM and Tefferi A: Chronic myelomonocytic leukemia: 2016 update on diagnosis, risk stratification, and management. Am J Hematol 91: 631-642, 2016.

16. Itzykson R, Kosmider O, Renneville A, Gelsi-Boyer V, Meggendorfer M, Morabito M, Berthon C, Adès L, Fenaux P, Beyne-Rauzy O, Vey N, et al: Prognostic score including gene mutations in chronic myelomonocytic leukemia. J Clin Oncol 31: 2428-2436, 2013.

17. Tang G, Zhang L, Fu B, Hu J, Lu X, Hu S, Patel A, Goswami M, Khoury JD, Garcia-Manero G, et al: Cytogenetic risk stratification of 417 patients with chronic myelomonocytic leukemia from a single institution. Am J Hematol 89: 813-818, 2014.

18. Calvo X, Nomdedeu M, Santacruz R, Martinez N, Costa D, Pereira A, Estrada N, Xicoy B, Esteve J and Nomdedeu B: Comparison of three prognostic scoring systems in a series of 146 cases of chronic myelomonocytic leukemia (CMML): MD Anderson prognostic score (MDAPS), CMML-specific prognostic scoring system (CPSS) and Mayo prognostic model. A detailed review of prognostic factors in CMML. Leuk Res: S0145-2126(15)30324-6, 2015.

19. Such E, Cervera J, Costa D, Solé F, Vallespí T, Luño E, Collado R, Calasanz MJ, Hernández-Rivas JM, Cigudosa JC, et al: Cytogenetic risk stratification in chronic myelomonocytic leukemia. Haematologica 96: 375-383, 2011.

20. Patnaik MM, Itzykson R, Lasho TL, Kosmider O, Finke CM, Hanson CA, Knudson RA, Ketterling RP, Tefferi A and Solary E: ASXL1 and SETBP1 mutations and their prognostic contribution in chronic myelomonocytic leukemia: A two-center study of 466 patients. Leukemia 28: 2206-2212, 2014.

21. Patnaik MM, Barraco D, Lasho TL, Finke CM, Hanson CA, Ketterling RP, Gangat N and Tefferi A: DNMT3A mutations are associated with inferior overall and leukemia-free survival in chronic myelomonocytic leukemia. Am J Hematol 92: 56-61, 2017.

22. Jaiswal S, Fontanillas P, Flannick J, Manning A, Grauman PV, Mar BG, Lindsley RC, Mermel CH, Burtt N, Chavez A, et al: Age-related clonal hematopoiesis associated with adverse outcomes. N Engl J Med 371: 2488-2498, 2014.

23. Jankowska AM, Makishima H, Tiu RV, Szpurka H, Huang Y, Traina F, Visconte V, Sugimoto Y, Prince C, O'Keefe C, et al: Mutational spectrum analysis of chronic myelomonocytic leukemia includes genes associated with epigenetic regulation: UTX, EZH2, and DNMT3A. Blood 118: 3932-3941, 2011.

24. Kosmider O, Gelsi-Boyer V, Ciudad M, Racoeur C, Jooste V, Vey N, Quesnel B, Fenaux P, Bastie JN, Beyne-Rauzy O, et al: TET2 gene mutation is a frequent and adverse event in chronic myelomonocytic leukemia. Haematologica 94: 1676-1681, 2009.

25. Patnaik MM, Lasho TL, Vijayvargiya P, Finke CM, Hanson CA, Ketterling RP, Gangat N and Tefferi A: Prognostic interaction between ASXL1 and TET2 mutations in chronic myelomonocytic leukemia. Blood Cancer J 6: e385, 2016.

26. Bejar R, Lord A, Stevenson K, Bar-Natan M, Pérez-Ladaga A, Zaneveld J, Wang H, Caughey B, Stojanov P, Getz G, et al: TET2 mutations predict response to hypomethylating agents in myelodysplastic syndrome patients. Blood 124: 2705-2712, 2014.

27. Eissa H, Gooley TA, Sorror ML, Nguyen F, Scott BL, Doney K, Loeb KR, Martin PJ, Pagel JM, Radich JP, et al: Allogeneic hematopoietic cell transplantation for chronic myelomonocytic leukemia: Relapse-free survival is determined by karyotype and comorbidities. Biol Blood Marrow Transplant 17: 908-915, 2011.

28. Aribi A, Borthakur G, Ravandi F, Shan J, Davisson J, Cortes J and Kantarjian H: Activity of decitabine, a hypomethylating agent, in chronic myelomonocytic leukemia. Cancer 109: 713-717, 2007.

29. Courville EL, Wu Y, Kourda J, Roth CG, Brockmann J, Muzikansky A, Fathi AT, de Leval L, Orazi A and Hasserjian RP: Clinicopathologic analysis of acute myeloid leukemia arising from chronic myelomonocytic leukemia. Mod Pathol 26: 751-761, 2013.

30. Wijermans PW, Rüter B, Baer MR, Slack JL, Saba HI and Lübbert M: Efficacy of decitabine in the treatment of patients with chronic myelomonocytic leukemia (CMML). Leuk Res 32: 587-591, 2008.

31. Damaj G, Duhamel A, Robin M, Beguin Y, Michallet M, Mohty M, Vigouroux S, Bories P, Garnier A, El Cheikh J, et al: Impact of azacitidine before allogeneic stem-cell transplantation for myelodysplastic syndromes: A study by the Société Française de Greffe de Moelle et de Thérapie-Cellulaire and the GroupeFrancophone des Myélodysplasies. J Clin Oncol 30: 4533-4540, 2012. 
32. Kantarjian HM, O'Brien S, Huang X, Garcia-Manero G, Ravandi F, Cortes J, Shan J, Davisson J, Bueso-Ramos CE and Issa JP: Survival advantage with decitabine versus intensive chemotherapy in patients with higher risk myelodysplastic syndrome: Comparison with historical experience. Cancer 109: $1133-1137,2007$

33. Duchmann M, Braun T, Micol JB, Platzbecker U, Park S, Pilorge S, Beyne-Rauzy O, Vey N, Sébert M, Gruson B, et al: Validation of response assessment according to international consortium for MDS/MPN criteria in chronic myelomonocytic leukemia treated with hypomethylating agents. Blood Cancer J 7: e562, 2017.

34. Deng Q, Li JY, Liu PJ and Zhao MF: Successful management of acute myeloid leukemia transformed from chronic myelomonocytic leukemia in the elderly by a combination regimen of decitabine and cytarabine, aclarubicin and granulocyte colony-stimulating factor: A case report. Oncol Lett 9: 1217-1220, 2015.

35. Padron E, Dezern A, Andrade-Campos M, Vaddi K, Scherle P, Zhang Q, Ma Y, Balasis ME, Tinsley S, Ramadan H, et al: A multi-institution phase I trial of ruxolitinib in patients with chronic myelomonocytic leukemia (CMML). Clin Cancer Res 22: 3746-3754, 2016.

36. Padron E, Painter JS, Kunigal S, Mailloux AW, McGraw K, McDaniel JM, Kim E, Bebbington C, Baer M, Yarranton G, et al: GM-CSF-dependent pSTAT5 sensitivity is a feature with therapeutic potential in chronic myelomonocytic leukemia. Blood 121: 5068-5077, 2013.
37. Komrokji RS, Seymour JF, Roberts AW, Wadleigh M, To LB, Scherber R, Turba E, Dorr A, Zhu J, Wang L, et al: Results of a phase 2 study of pacritinib (SB1518), a JAK2/JAK2(V617F) inhibitor, in patients with myelofibrosis. Blood 125: 2649-2655, 2015.

38. Emanuel PD, Bates LJ, Castleberry RP, Gualtieri RJ and Zuckerman KS: Selective hypersensitivity to granulocyte-macrophage colony-stimulating factor by juvenile chronic myeloid leukemia hematopoietic progenitors. Blood 77: 925-929, 1991.

39. Savona MR, Malcovati L, Komrokji R, Tiu RV, Mughal TI, Orazi A, Kiladjian JJ, Padron E, Solary E, Tibes R, et al: An international consortium proposal of uniform response criteria for myelodysplastic/myeloproliferative neoplasms (MDS/MPN) in adults. Blood 125: 1857-1865, 2015.

This work is licensed under a Creative Commons Attribution-NonCommercial-NoDerivatives 4.0 International (CC BY-NC-ND 4.0) License. 